\title{
Papain and its inhibitor E-64 reduce camelid semen viscosity without impairing sperm function and improve post-thaw motility rates
}

by Kershaw, C.M., Evans, G., Rodney, R. and Maxwell, W.M.C.

Copyright, Publisher and Additional Information: This is the author accepted manuscript. The final published version (version of record) is available online via Csiro Please refer to any applicable terms of use of the publisher.

DOI: $\underline{0.1071 / R D 15261}$

Harper Adams

University

Kershaw, C.M., Evans, G., Rodney, R. and Maxwell, W.M.C.2016. Papain and its inhibitor E-64 reduce camelid semen viscosity without impairing sperm function and improve post-thaw motility rates. Reproduction, Fertility and Development 


\section{IIIII) Reproduction,} Fertility and Development

\section{Papain and its inhibitor E-64 reduce camelid semen viscosity without impairing sperm function and improve post-thaw motility rates}

\begin{tabular}{|r|l|}
\hline Journal: & Reproduction, Fertility and Development \\
\hline Manuscript ID & RD15261.R2 \\
\hline Manuscript Type: & Research paper \\
\hline Complete List of Authors: & $\begin{array}{l}\text { Kershaw, Claire; Harper Adams University, Animal Production, Welfare and } \\
\text { Veterinary Sciences } \\
\text { Evans, Gareth; The University of Sydney, Faculty of Veterinary Science } \\
\text { Rodney, Rachael; The University of Sydney, Faculty of Veterinary Science } \\
\text { Maxwell, Chis; The University of Sydney, Faculty of Veterinary Science }\end{array}$ \\
\hline Keyword: & $\begin{array}{l}\text { artificial insemination, assisted reproductive technology, cryopreservation, } \\
\text { seminal plasma, sperm }\end{array}$ \\
\hline
\end{tabular}




\section{Papain and its inhibitor E-64 reduce camelid semen viscosity without}

\section{2 impairing sperm function and improve post-thaw motility rates}

3
4
C. M. Kershaw, G. Evans ${ }^{b}$, R. Rodney ${ }^{c}$, W.M.C. Maxwell ${ }^{b}$
5
$6{ }^{a}$ Department of Animal Production, Welfare and Veterinary Sciences, Harper Adams University,
7 Newport, Shropshire, UK
$8{ }^{b}$ Faculty of Veterinary Science, The University of Sydney, Camperdown, Sydney, NSW 2006
9 Australia

10

11

12 Veterinary Sciences, Harper Adams University, Newport, Shropshire, UK. Tel: +44 (0)1952815517; email:

Ckershaw@harper-adams.ac.uk

15 Abridged Title: Cryopreservation of papain-treated alpaca semen 
16 Abstract

17 In camelids, the development of assisted reproductive technologies is impaired by the viscous nature of the semen. The protease papain has shown promise in reducing viscosity, although its effect on sperm integrity is unknown. This study determined the optimal papain concentration and exposure time to reduce seminal plasma viscosity and investigated the effect of papain and its inhibitor E-64 on sperm function and cryopreservation in alpacas.

Papain $\left(0.1 \mathrm{mg} / \mathrm{mL}, 20 \mathrm{~min}, 37^{\circ} \mathrm{C}\right)$ eliminated alpaca semen viscosity whilst maintaining sperm motility, viability, acrosome integrity and DNA integrity. Furthermore E-64 $\left(10 \mu \mathrm{m}, 5 \mathrm{~min}, 37^{\circ} \mathrm{C}\right)$ inhibited the papain without impairing sperm function.. Cryopreserved, papain-treatedalpaca spermatozoa, exhibited higher total motility rates after chilling and at $0 \mathrm{~h}$ and $1 \mathrm{~h}$ post-thaw compared to control (untreated) samples.

Papain and E-64 are effective at reducing alpaca seminal plasma viscosity without impairing sperm integrity and improve post-thaw motility rates of cryopreserved alpaca sperm. The use of papain and E-64 to eliminate the viscous component of camelid semen may aid the development of assisted reproductive technologies in camelids. 


\section{Introduction}

The development of semen cryopreservation and other assisted reproductive technologies in camelids is hindered by the viscous nature of camelid seminal plasma. The highly viscous semen does not evenly homogenise with cryodiluents on mixing, preventing adequate contact between the cryoprotectants and sperm membrane during freezing. It is therefore necessary to reduce seminal plasma viscosity without impairing sperm function prior to freezing in order to improve the success and enhance the development of cryopreservation protocols in camelids.

In dromedary (Skidmore and Billah, 2006) and Bactrian (Niasari-Naslaji et al. 2007) camels the viscous seminal plasma partially liquefies within 20-30 min of ejaculation facilitating mixing of the diluent with the semen whereas the semen of new world camelids (alpaca, llama, vicuna and guanaco) is viscous for $18-24 \mathrm{~h}$ after ejaculation (Garnica et al. 1993). The relatively rapid liquefaction of camel semen has enabled some success in sperm cryopreservation particularly in the Bactrian camel (Niasari-Naslaji et al, 2007) although pregnancy rates with frozen-thawed semen are still not commercially acceptable in the Dromedary (Deen et al. 2003). Conversely, in alpacas and Ilamas, cryopreservation of "non-liquefied" viscous semen is unsuccessful with low sperm motility obtained post-thaw (Adams et al. 2009).

The cause of the viscosity within seminal plasma is unknown. It has been postulated that glycosaminoglycans (GAGs) are responsible (Ali et al. 1976; Perk 1962). However, while GAGs are abundant in alpaca seminal plasma (Kershaw-Young et al. 2012), enzymes that degrade GAGs do not completely eliminate the viscosity of semen (Kershaw-Young et al. 2013) . Conversely, generic proteases including papain and proteinase $\mathrm{K}$, trypsin, fibrinolysin, and collagenase (Bravo et al. $2000^{\text {a }}$; Bravo et al. 1999; Giuliano, et al. 2010; Morton et al. 2008) all reduce the viscosity of alpaca seminal plasma, suggesting that proteins, not GAGs, are the predominant cause of the viscosity. In Bactrian camels where seminal plasma viscosity is reportedly lower than dromedary or alpaca seminal plasma with little gelatinous material (Zhao, 2000) a reduction of viscosity via 
56

57

mechanical stirring with a clip, aids the success of cryopreservation.(Niasari-Naslaji et al. 2007).

Consequently, research on liquid and frozen storage of camelid semen has focussed on reducing the viscosity of the seminal plasma by mechanical and enzymatic methods (Bravo et al. 2000; Bravo et al. 1999; Giuliano et al. 2010; Morton et al. 2008). Trypsin, fibrinolysin and proteinase K (Bravo et al. 2000 ; Kershaw-Young et al. 2013) all have detrimental effects on sperm function and integrity. Some success has been achieved using collagenase (Conde et al. 2008; Giuliano et al. 2010) but other studies have reported deleterious effects of collagenase on sperm motility (Morton et al. 2008). Papain, the cysteine protease enzyme present in papaya (Carica papaya) has shown promise as a reducer of viscosity in seminal plasma however the acrosomes of alpaca spermatozoa were impaired when exposed to this enzyme over $10 \mathrm{~min}$ to $1 \mathrm{~h}$ at concentrations of $0.5-4 \mathrm{mg} / \mathrm{ml}$ (Morton et al. 2008). Conversely papain rapidly reduced seminal plasma viscosity with no effect on sperm motility, viability, DNA integrity or acrosome integrity when added to the viscous semen at a low final concentration of $0.1 \mathrm{mg} / \mathrm{ml}$ (Kershaw-Young et al. 2013).

Following enzymatic degradation of viscosity, the downstream application of cryopreservation often entails prolonged chilling of the viscosity-reduced semen over a two hour period prior to freezing, resulting in prolonged exposure of the spermatozoa to any enzymes present in the "liquefaction" diluent. Consequently, in order to overcome the negative effects of prolonged exposure to papain on the acrosome integrity of alpaca spermatozoa, it would be advantageous to inhibit the papain following liquefaction. Trans-Epoxysuccinyl-L-leucylamido(4guanidino)butane (E-64) is a protease inhibitor that binds to the active thiol group of cysteine proteases, including papain, collagenase and trypsin, substantially reducing their function (Barrett et al. 1982; Barrett et al. 1981; Tamai et al. 1981). The specific nature and low toxicity of this inhibitor make it a promising option for inhibiting papain and reducing the potential impacts of long term exposure on spermatozoa. 
81 As the viscous seminal plasma is currently the major impediment to the success of

82 cryopreservation in camelids, a reduction in seminal plasma viscosity whilst maintaining sperm

83 function could aid freezing and thawing. Consequently the potential of papain and its inhibitor E-

8464 to reduce viscosity and improve motility rates after cryopreservation merits investigation.

In order to determine the potential use of papain as a viscosity reducing enzyme in camelid semen, we investigated (1) the effect of papain concentration and time, and the inhibitor E-64, on alpaca seminal plasma viscosity and sperm function,) and (2)the effect of papain treatment of semen on the viscosity of semen and motility of alpaca sperm during and after cryopreservation.

\section{Materials and Methods}

91

\section{Animals}

All experiments were performed using male alpacas under authorization from the University of Sydney animal ethics committee. Animals were housed in paddocks on natural pasture with water provided ad libitum and their diets supplemented with Lucerne hay. All males were $>3 \mathrm{y}$, had a body condition score $>3$ and had testes more than $3 \mathrm{~cm}$ long (Tibary and Vaughan, 2006).

\section{Experimental Design}

Three experiments were conducted. Experiments 1 and 2 determined the effect of concentration and time of exposure to papain (exp 1), and the papain inhibitor E-64 (exp 2), on the viscosity of alpaca seminal plasma and sperm function. Experiment 3 investigated the effect of treatment of spermatozoa with papain (Sigma-Aldrich, St Louis, MO, USA) and E-64 (Sigma-Aldrich, St Louis, MO, USA ) on the total motility of alpaca sperm during chilling, freezing and post-thaw in order to investigate the effect of enzyme reduction in viscosity on the success of alpaca sperm 
cryopreservation.

Experiment 1: Optimisation of Papain Concentration and Time

Semen was collected from six male alpacas ( $\geq 2$ ejaculates/male, $n=15$ ) using an artificial vagina

fitted inside a mannequin (Morton et al. 2010 ). Within 5 min of collection, semen was assessed for volume, viscosity, and total motility and concentration of spermatozoa as described below.

$\times 10^{6}$ spermatozoa/ $\mathrm{mL}$ were used. Following collection, $1 \mathrm{~mL}$ of semen was diluted 1:1 in prewarmed Tris-citrate-fructose buffer ( $300 \mathrm{mM}$ Tris, $94.7 \mathrm{mM}$ citric acid, $27.8 \mathrm{mM}$ fructose) (Evans and Maxwell, 1987) and pipetted up and down six times to ensure even mixing. The diluted semen was allocated to four treatment groups: (1) $390 \mu$ l diluted semen plus $10 \mu \mathrm{l} 0.02 \mathrm{M}$ PBS (control), (2) $390 \mu l$ diluted semen plus $10 \mu \mathrm{l} 0.04 \mathrm{mg} / \mathrm{mL}$ papain (final concentration $0.001 \mathrm{mg} / \mathrm{ml}$ ), min after treatment.

\section{Experiment 2: Inhibition of Papain with E-64}

Semen was collected from six male alpacas ( $\geq 2$ ejaculates/male, $n=15$ ) and assessed and selected as for experiment 1. Semen was then diluted 1:1 in pre-warmed Tris-citrate-fructose buffer (Evans and Maxwell, 1987). In a preliminary experiment we determined that $0.1 \mathrm{mg} / \mathrm{mL}$ papain incubated with $10 \mu \mathrm{M} \mathrm{N}$-(trans-Epoxysuccinyl)-L-leucine 4-guanidinobutylamide (E-64) at $37^{\circ} \mathrm{C}$ for 5 min then incubated with alpaca semen for $20 \mathrm{~min}$ at $37^{\circ} \mathrm{C}$ was ineffective at reducing viscosity, indicating that $10 \mu \mathrm{M} \mathrm{E}-64$ for $5 \mathrm{~min}$ at $37^{\circ} \mathrm{C}$ inhibits papain as described previously (Barrett et al. 1982). 
131 Consequently, $10 \mu \mathrm{M} \mathrm{E}-64$ for $5 \mathrm{~min}$ at $37^{\circ} \mathrm{C}$ was used in the present study.

132 Diluted semen samples were allocated to two treatment groups, (1) $792 \mu$ l diluted semen plus $8 \mu l$

1330.02 M PBS (control; treatment 1) and (2) $792 \mu$ l diluted semen plus $8 \mu 10.0 \mathrm{mg} / \mathrm{mL}$ papain (final

134 concentration $0.1 \mathrm{mg} / \mathrm{mL}$; treatment 2 ), and incubated at $37^{\circ} \mathrm{C}$ for $20 \mathrm{~min}$ in a water bath. Each

135 aliquot was then divided further into two treatment groups, (1) $297 \mu$ l semen plus $3 \mu$ l 0.02M PBS

136 (control; treatment A) and (2) $297 \mu$ l semen plus $3 \mu \mathrm{l} 1 \mathrm{mM}$ E-64 (final concentration $10 \mu \mathrm{M}$;

137 treatment $\mathrm{B}$ ), and incubated at $37^{\circ} \mathrm{C}$ for $5 \mathrm{~min}$ in a water bath. This resulted in four samples for

138 assessment: 1A (no papain, no E-64), 1B (no papain, E-64 treatment,) 2A (papain treatment, no E-

139 64), 2B (papain treatment, E-64 treatment). Semen viscosity and total motility, acrosome

140 integrity, viability and DNA integrity of spermatozoa were assessed immediately after dilution (0

$141 \mathrm{~min})$, after papain or PBS but prior to E-64 treatment (20 min), and after E-64 or PBS treatment

142 (25 $\min )$.

Experiment 3: Cryopreservation of Papain-treated Semen

Semen was collected from four male alpacas ( $\geq 2$ ejaculates/male, $n=10$ ) using an artificial vagina

(Morton et al. 2010 ) and assessed for volume, viscosity, and total motility and concentration of

spermatozoa as described below. Only samples with a volume $>1 \mathrm{~mL}$, viscosity $\geq 15 \mathrm{~mm}$, total

motility $\geq 50 \%$ and concentration $\geq 40 \times 10^{6}$ spermatozoa/ $\mathrm{mL}$ were used. Following collection, semen was divided into 2 aliquots and diluted 1:1 in either pre-warmed Tris-citrate-fructose (fructose) extender (300 mM Tris, 94.7 mM citric acid, 27.8 mM fructose, pH 6.9) (Evans and Maxwell, 1987) or 11\% lactose extender (11\% lactose w/v, pH 6.9 (Morton et al. 2007) as used

152 previously for camelid spermatozoa (Morton et al. 2007; Niasari-Naslaji et al. 2006) and pipetted

153 up and down six times to ensure even mixing. Diluted semen samples were allocated to two

154 treatment groups (1) $0.1 \mathrm{mg} / \mathrm{ml}$ papain (final concentration) and (2) PBS (control) for 20min at

$15537^{\circ} \mathrm{C}$. Papain-treated samples were then incubated with $10 \mu \mathrm{M}$ E-64 (final concentration) and 
control samples with PBS for $5 \mathrm{~min}$ at $37^{\circ} \mathrm{C}$. Next, fructose-diluted samples were re-extended (1:1) with pre-warmed $\left(37^{\circ} \mathrm{C}\right)$ tris-citrate-fructose freezing extender (300 mM Tris, $94.7 \mathrm{mM}$ citric acid, $27.8 \mathrm{mM}$ fructose, $20 \%$ egg yolk, $12 \%$ glycerol) and lactose-diluted samples were re-extended (1:1) with pre-warmed lactose freezing extender (11\% lactose, $20 \%$ egg yolk, $12 \%$ glycerol). Final egg yolk and glycerol concentrations were $10 \%$ and $6 \%$, respectively. Samples were chilled to $4^{\circ} \mathrm{C}$ over $2 \mathrm{~h}$ then frozen as $200 \mu \mathrm{l}$ pellets on dry ice as described previously (Evans and Maxwell, 1987), then stored in liquid nitrogen. Total motility of spermatozoa and semen viscosity were assessed prior to dilution (pre-dilution) immediately after dilution (post-dilution), following papain and E64 treatment (post-treatment) and after chilling to $4^{\circ} \mathrm{C}$ but before freezing (post-chill). After 4 weeks storage in liquid nitrogen, the frozen pellets were thawed in glass tubes by vigorous shaking in a water bath at $37^{\circ} \mathrm{C}$. Samples were then diluted with either pre-warmed fructose extender (samples cryopreserved in fructose extender) or $11 \%$ lactose extender (samples cryopreserved in lactose extender) to a final seminal plasma concentration of $10 \%$ as this concentration is optimal to prolong motility, preserve acrosome integrity and maintain viability of alpaca spermatozoa (Kershaw-Young and Maxwell, 2011) and total sperm motility was assessed at 0,1 and 3 h post-thaw.

\section{Analysis of semen viscosity and sperm parameters}

\section{Viscosity of semen and concentration and motility of spermatozoa}

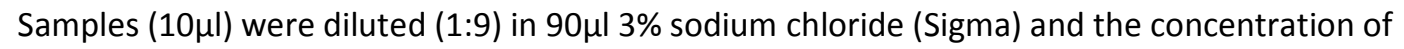
spermatozoa was assessed using a haemocytometer (Evans and Maxwell, 1987). Viscosity was assessed using the thread test (Bravo et al. $2000^{\mathrm{a}}$ ). Briefly, $50 \mu \mathrm{l}$ of semen or sample was drawn into a pipette, $25 \mu \mathrm{l}$ was pipetted onto a warm glass slide and the pipette was lifted vertically forming a thread of sample. The length at which the thread snapped was recorded as the measurement of viscosity. As the viscosity of seminal plasma varies between males, the initial 
182 viscosity measurement $(\mathrm{mm})$ was taken as $100 \%$ viscosity. Subsequent measurements were

183 recorded in $\mathrm{mm}$ then converted to a percentage value of the initial measurement for data

184 analysis. Total motility of spermatozoa was assessed subjectively at X 100 magnification under

185 phase contrast microscopy (Olympus, Tokyo, Japan) by placing $10 \mu \mathrm{L}$ of semen or sample on a

186 warm slide and covering with a warm coverslip (Evans and Maxwell, 1987). All motile sperm,

187 whether oscillatory or progressive, were considered motile and used to generate a value for total

188 motility.

189

\section{Acrosome integrity of spermatozoa, experiment 1}

Acrosome integrity of spermatozoa was assessed as described previously (Kershaw-Young and

Maxwell, 2011). Briefly, $20 \mu$ l of sample was fixed in $0.1 \%$ neutral buffered formalin and stored at

$4^{\circ} \mathrm{C}$ until analysis. Seminal plasma was removed by centrifugation and the spermatozoa

resuspended in $0.02 \mathrm{M}$ PBS to $10 \times 10^{6} / \mathrm{mL}$. Twenty $\mu \mathrm{L}$ of resuspended spermatozoa was mixed

with $4 \mu \mathrm{L}$ fluorescent isothiocyanate-conjugated lectin from Arachis hypogaea (working

a glass slide and covered with a $22 \times 50 \mathrm{~mm}$ coverslip. A minimum of 200 spermatozoa were observed under phase contrast at X 400 magnification using the Olympus BX51 fluorescence microscope with the U-MWIB filter (excitation filter 460-495nm, emission filter 510-550 nm, 505 $\mathrm{nm}$ dichromatic mirror). Acrosomes were considered not intact if the acrosome stained green, and considered intact if there was no staining or if the equatorial segment was stained green.

202

\section{Acrosome integrity of spermatozoa, experiment 2}

204 Acrosome integrity was assessed based on previously described methods (Leahy et al. 2010).

205 Semen was diluted in $1 \mathrm{~mL} 0.02 \mathrm{M}$ PBS to a final concentration of $1 \times 10^{6} \mathrm{spermatozoa} / \mathrm{mL}$ then

206 incubated with $10 \mu \mathrm{I}$ FITC-PNA (working concentration $40 \mu \mathrm{g} / \mathrm{mL}$ ) at $37^{\circ} \mathrm{C}$ for $15 \mathrm{~min}$,. The samples

207 were fixed with $10 \mu \mathrm{l} 10 \%$ neutral buffered formalin (final concentration $0.1 \%$ ). Fluorescence was 
detected using a FACScan flow cytometer (Becton Dickinson, San Jose, CA), equipped with an argon ion laser (488 nm, $15 \mathrm{~mW}$ ) for excitation and acquisitions were made using CellQuest 3.3 software (Becton Dickinson, San Jose, CA). A minimum of 5,000 gated events were recorded. Acrosomes were considered not intact if the acrosome stained green, and considered intact if there was no staining.

\section{Viability of spermatozoa, experiment 2}

Viability, measured as spermatozoa with non-impaired membranes, was assessed as described previously (Kershaw-Young and Maxwell, 2011). Briefly, samples were fixed in $1 \mathrm{~mL} 0.1 \%$ neutral buffered formalin in $0.02 \mathrm{M} \mathrm{PBS}$ at a final concentration of $1 \times 10^{6}$ spermatozoa $/ \mathrm{mL}$ and stored at $4^{\circ} \mathrm{C}$ overnight. Next day, samples were incubated with $10 \mu \mathrm{l}$ Syto-16 (Molecular Probes, Eugene, $\mathrm{OR}$, USA; working concentration $10 \mu \mathrm{M}$ ) at room temperature for $20 \mathrm{~min}$, then $10 \mu \mathrm{L}$ Propidium iodide ( $\mathrm{PI}$, Molecular Probes, Eugene, OR, USA, working concentration $240 \mu \mathrm{M}$ ) at room temperature for a further $10 \mathrm{~min}$. Viability of spermatozoa was determined using a FACScan flow cytometer as described above. Spermatozoa that stained positive for Syto-16 and negative for PI were deemed viable, and those that stained negative for Syto-16 and positive for PI were deemed non-viable.

\section{DNA Integrity of spermatozoa}

The integrity of sperm DNA was assessed as described previously (Kershaw-Young and Maxwell, 2011). Briefly, samples were snap frozen in liquid nitrogen and stored at $-20^{\circ} \mathrm{C}$ until analysis. Samples were resuspended to a concentration of $10 \times 10^{6}$ spermatozoa $/ \mathrm{mL}$, smeared onto a glass slide and fixed in $100 \%$ ice cold methanol. Next, slides were incubated with Terminal deoxynucleotidyl transferase dUTP nick end labelling (TUNEL) reaction mixture (Roche Applied Science, Mannheim, Germany) in a humidified chamber at $37^{\circ} \mathrm{C}$ for $1 \mathrm{~h}$, then counterstained with DAPI (Vector Laboratories, CA, USA). A minimum of 200 spermatozoa was assessed with the BX51 
234

fluorescence microscope, as described for acrosome integrity. Sperm DNA was considered nonfragmented if there was no fluorescence, and fragmented if the sperm head stained green.

\section{Statistical Analysis}

Data were analysed using Genstat version 16 (VSN International, Hemel Hempstead, UK).

For experiment 1 , viscosity of semen, and total motility and acrosome integrity of spermatozoa were analysed using a REML linear mixed model where papain concentration, incubation time and their interaction were specified as the fixed effect in the model.

In experiment 2, viscosity of semen, and total motility, acrosome integrity, viability and DNA integrity of spermatozoa were analysed using a REML linear mixed model. Male, replicate and papain treatment were used as random effects while the individual treatment was used as the fixed effect in the model. Observations with residuals more than three standard deviations from the mean were considered statistical outliers and were removed prior to analysis. In all cases statistical significance was defined as $P<0.05$.

In experiment 3, viscosity of sample and total motility of sperm were analysed using a REML linear mixed model where treatment, time and their interaction were specified as the fixed effects and male, replicate and treatment were used as the random effects.

\section{Results}

\section{Experiment 1: Optimisation of Papain Concentration and Time}

Papain treatment significantly reduced the viscosity of alpaca seminal plasma $(P<0.001$; Fig. 1$)$.

At 5,10 and 20 min after treatment viscosity was less in $0.1 \mathrm{mg} / \mathrm{mL}$ papain-treated samples compared to other treatment groups. Viscosity was completely eliminated in samples containing $0.1 \mathrm{mg} / \mathrm{mL}$ papain within $20 \mathrm{~min}$ of treatment, and with $0.01 \mathrm{mg} / \mathrm{mL}$ papain within $30 \mathrm{~min}$. Viscosity was not completely eliminated within $30 \mathrm{~min}$ in $0.001 \mathrm{mg} / \mathrm{mL}$ and $0 \mathrm{mg} / \mathrm{mL}$ (control) papain- 
259 treated samples. However, after 30 min incubation, all papain-treated samples had less viscosity

260 than control samples. Viscosity reduced significantly over time in all treatment groups, although

261 the reduction was most rapid for samples treated with $0.1 \mathrm{mg} / \mathrm{mL}$ papain $(p<0.001 ;$ Fig. 1$)$.

262 Motility of spermatozoa differed between treatments at each time point $(P=0.01 ;$ Table 1$)$. A 263 decrease in motility of spermatozoa was observed from 0 to 30 min post treatment in all groups $264(P=0.01 ;$ Table 1$)$. In samples treated with $0.1 \mathrm{mg} / \mathrm{mL}$ papain, the decline in total motility was 265 slower than other treatment groups and consequently at 10 and 20 min after treatment, motility 266 was higher in samples treated with $0.1 \mathrm{mg} / \mathrm{mL}$ papain than control samples, and at 30 min motility 267 was higher in samples treated with $0.1 \mathrm{mg} / \mathrm{mL}$ papain than in all other treatment groups.

The percentage of spermatozoa with intact acrosomes differed between concentrations of papain $(p<0.001)$ and between time points $(p=0.007)$ although there was no interaction. Due to lack of interaction, comparisons of concentration were made using data pooled across all time points, and comparisons of time were made using data pooled across all concentrations of papain. The percentage of spermatozoa with intact acrosomes (mean \pm sem) was higher in samples treated with $0.1 \mathrm{mg} / \mathrm{mL}$ papain $(53.9 \pm 0.50)$ compared to those containing $0(51.7 \pm 0.58), 0.001(51.9 \pm$ $0.59)$ and $0.01 \mathrm{mg} / \mathrm{mL}$ papain $(52.3 \pm 0.59)$. Acrosome integrity decreased significantly over time and was greater at $0(52.7 \pm 0.51), 5(53.48 \pm 0.60)$ and $10 \mathrm{~min}(52.6 \pm 0.71)$ compared to $30 \mathrm{~min}$ $(51.4 \pm 0.71 \%)$ after treatment. Acrosome integrity at $20 \mathrm{~min}$ post-treatment $(52.1 \pm 0.63 \%) \underline{\text { did }}$ not differ from the other time points.

\section{Experiment 2: Inhibition of Papain with E-64}

As observed in experiment 1 , the viscosity of seminal plasma was completely eliminated within 20 min of treatment with $0.1 \mathrm{mg} / \mathrm{mL}$ papain. Viscosity (mean $\mathrm{mm} \pm$ sem) was significantly lower in papain-treated samples compared with the control $(P<0.001)$ at both 20min (pre-E64; papain- 
treated $0.0 \pm 0.0$ vs. control $78.7 \pm 5.41$ ) and $25 \mathrm{~min}$ (post-E64; papain-treated $0.0 \pm 0.0$ vs. control $66.5 \pm 3.29)$ of treatment. The papain inhibitor E64 did not affect viscosity $(P=0.734)$.

The total motility of spermatozoa did not differ between treatments $(p=0.505)$, nor was there any treatment $x$ time interaction. Total motility (mean $\% \pm$ sem) was not different between the control (50.7 \pm 1.16$)$, E64 only ( $46.7 \pm 2.05)$, papain only $(49.2 \pm 1.40)$, and papain with E64 (47.3 \pm from $0(54.7 \pm 1.50), 20(50.3 \pm 1.92)$ and $25 \mathrm{~min}(46.8 \pm 1.47)$, although this was similar for all treatments.

The percentage of spermatozoa with intact acrosomes was higher in papain-treated samples (43.8 $\pm 2.71)$ compared to samples that were not treated with papain $(36.1 \pm 2.28 \% ; p<0.01)$ but was not affected by E64 treatment or time $(P>0.05)$. did not differ over time $(P>0.05)$. Viability (mean \pm sem) was similar in the control $(76.0 \pm 2.36)$, E64 only $(76.4 \pm 3.68)$, papain only $(76.6 \pm 2.72)$ and papain with E64 $(77.7 \pm 3.75)$ treatment groups.

The percentage of spermatozoa with intact DNA (mean \pm sem) was not different between control (97.5 \pm 0.22$)$, E64 only $(97.7 \pm 0.39)$, papain only $(97.6 \pm 0.25)$ and papain with E64 $(97.9 \pm 0.38)$ treated samples, and did not change over time $(P>0.05)$.

\section{Experiment 3: Cryopreservation of papain-treated semen}

Papain treatment significantly reduced seminal plasma viscosity $(P<0.001)$. Viscosity (mean $\mathrm{mm}$ \pm sem) did not differ between treatments prior to dilution $(56.3 \pm 9.11)$ and following dilution (33. $4 \pm 3.02)$ but was significantly lower in samples treated with fructose-papain $(0 \pm 0.0)$ and lactosepapain $(0 \pm 0.0)$ compared to the fructose control post-treatment $(24.9 \pm 5.81)$ and post-chill $(16.6$ $\pm 3.72)$ and the lactose control post-treatment $(26.5 \pm 6.13)$ and post-chill $(15.1 \pm 3.63)$. 
0.03; Table 2). Prior to, and following dilution, there were no differences between treatments. However, total motility was significantly lower in lactose control samples, both post-treatment and post-chill, compared to all other treatment groups. Additionally immediately post-thaw $(0 \mathrm{~h})$ total motility was significantly lower in lactose control samples than fructose-papain and lactosepapain treated samples whereas fructose control spermatozoa exhibited intermediate total motility. At 1 h post-thaw, total motility of fructose-papain treated spermatozoa was significantly higher than fructose-control samples and lactose control samples contained significantly less motile spermatozoa than all other treatments. At $3 \mathrm{~h}$ post-thaw there were no significant differences in the motility of spermatozoa between treatment groups. Total motility also differed between time points in each treatment group (Table 2). Generally, total motility of spermatozoa increased after dilution compared to pre-dilution, remained high post-treatment (except in lactose-control samples) then declined post-chill to intermediate levels, and declined further at $0 \mathrm{~h}$ and $1 \mathrm{~h}$ post-thaw. Motility was significantly less at $3 \mathrm{~h}$ post-thaw in all treatment groups compared to all other time points $(P<0.001)$.

\section{Discussion}

This study investigated: the effect of papain concentration and time, and the inhibitor E-64, on alpaca seminal plasma viscosity and sperm function, and the effect of papain treatment of semen on the success of cryopreservation in alpaca spermatozoa.

Alpaca seminal plasma viscosity was completely eliminated within 20 min of treatment using $0.1 \mathrm{mg} / \mathrm{mL}$ papain and within $30 \mathrm{~min}$ of treatment using $0.01 \mathrm{mg} / \mathrm{mL}$ papain. The reduction of seminal plasma viscosity for use within the Camelid industry must be rapid, reliable, effective and have no detrimental effect on sperm function and integrity. Previously sties havested that generic proteases including trypsin, fibrinolysin, and collagenase and papain were detrimental to sperm motility, viability and acrosome integrity in alpacas and llamas (Bravo et al. $2000^{\mathrm{a}}$; Morton et al. 2008). In the present study, papain concentrations of 0.1 to $0.001 \mathrm{mg} / \mathrm{ml}$ 
335

336

337

papain were was not detrimental to sperm motility and acrosome integrity within 30 min of treatment, suggesting indicating that the lower concentrations of papain used-were low enough to-effective in reducinge viscosity without causing sperm damage. Furthermore all seminal plasmasemen samples exhibited $0 \mathrm{~mm}$ viscosity within $20 \mathrm{~min}$ of treatment when treated with 0.1 $\mathrm{mg} / \mathrm{mL}$ papain indicating that this protocol is reliable and effective in $100 \%$ of samples tested. It is also worth noting that ejaculates used through the study ranged from 49.5 to $272 \times 10^{6}$ spermatozoa/mL (average $84.9 \times 10^{6} / \mathrm{mL}$ ), and therefore this protocol did not appear to impair sperm function irrespective of sperm concentration.

A the acrosome integrity of alpaca spermatozoa is thenes when following 10 to 60 min exposure exposed to $0.5-04 \mathrm{mg} / \mathrm{mL}$ papain for 10 to $60 \mathrm{~min}$, and despite attempts were made-to remove the papain using PureSperm gradient, this was ineffective in prevering acrosome damage was observed (Morton et al. 2008). As the cryopreservation of semen often involves chilling over a $2 \mathrm{~h}$ period prior to freezing, it is necessary to inhibit the papain following liquefaction in order to overcome any negative effects of prolonged papain exposure. Treatment with E-64 did not affect sperm motility, acrosome integrity, viability and DNA integrity suggesting that this inhibitor is not toxic to alpaca sperm. The specific nature and low toxicity of E-64 make it a suitable option for inhibiting papain in order to reduce any potential impacts of long term exposure on sperm, in particular the effect of prolonged papain exposure on acrosome integrity.

This study compared the effect of viscosity reduction on the motility of alpaca sperm following cryopreservation. The total motility of papain-E-64 treated alpaca spermatozoa was significantly greater after chilling to $4^{\circ} \mathrm{C}$ and at 0 and $1 \mathrm{~h}$ post-thaw implying that a reduction in seminal plasma viscosity prior to sperm cryopreservation is advantageous to the sperm. During cryopreservation it is essential that cryoprotectants such as egg yolk and glycerol are able to interact with or permeate the sperm membrane in order to enhance their protective capacity and reduce sperm damage. It is likely that, in the present study, the reduction in viscosity enabled the 
cryoprotectants to act accordingly as opposed to viscous semen in which the seminal plasma traps

362 the sperm preventing contact of the sperm membrane with the cryoprotectants.

363 Sperm motility rates after chilling ( $32 \%$ to $51 \%$ ) and immediately post thaw ( $13 \%$ to $25 \%)$ were

364 similar to those reported previously for epididymal alpaca sperm of 5-25\% (Morton et al. 2007;

365 Morton et al. 2010 ) and ejaculated alpaca sperm: 4 - 40\% (Bravo et al. 2000 ; Santiani et al. 2005)

366 Recently, our protocol using papain and E-64 to reduce seminal plasma viscosity has been utilised

367 to aid the cryopreservation of dromedary spermatozoa (Crichton et al. 2015). Papain treatment

368 successfully reduced viscosity enabling removal of the seminal plasma and subsequent

369 cryopreservation of cholesterol-supplemented spermatozoa obtained post-thaw motility rates of

$37044 \%$ (Crichton et al. 2015). This suggests that the viscosity reduction protocol developed in this

371 study has application in the development of camelid assisted reproductive technologies.

372

373

374

375

376

377

378

379

380

381

382

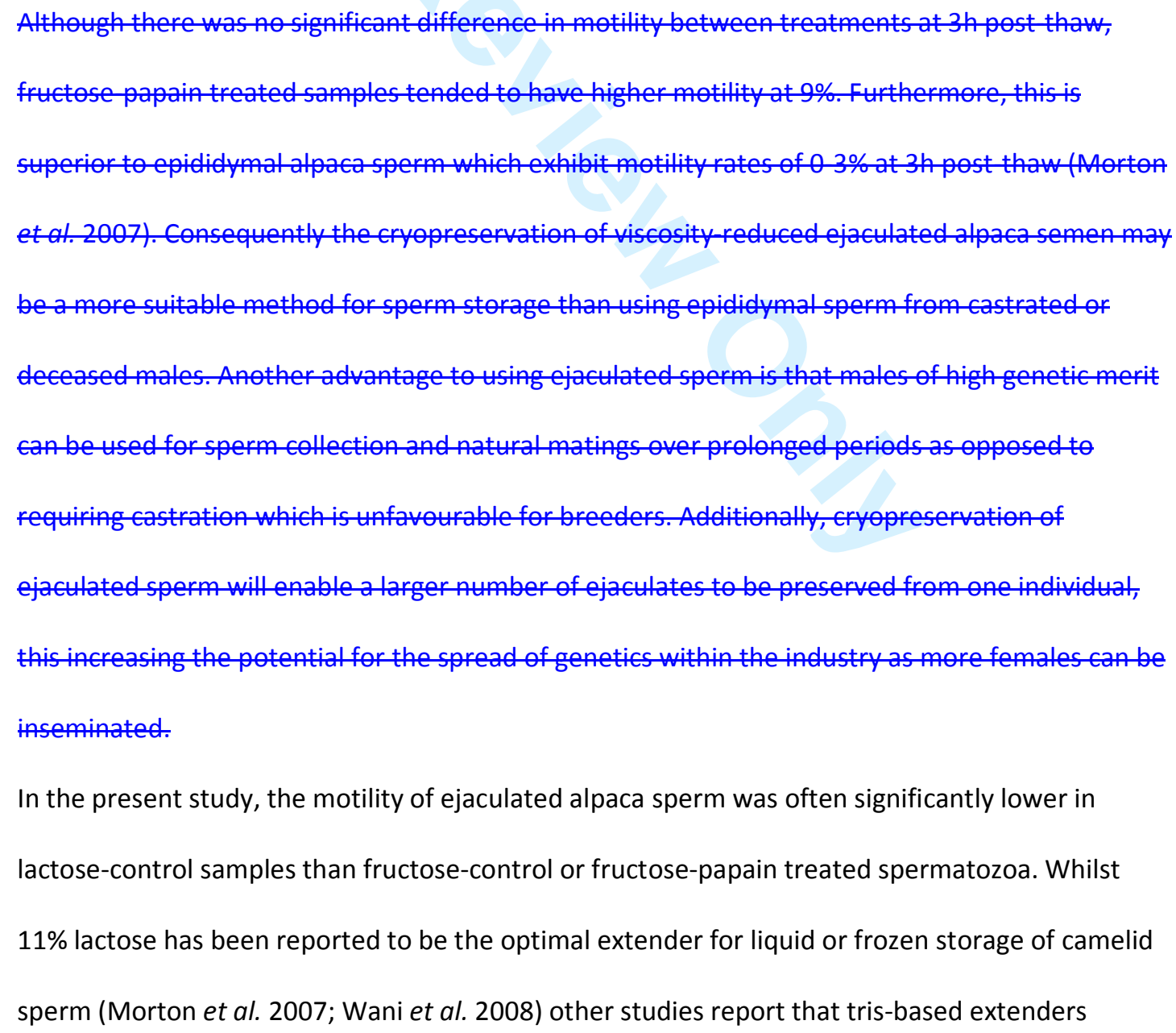

In the present study, the motility of ejaculated alpaca sperm was often significantly lower in lactose-control samples than fructose-control or fructose-papain treated spermatozoa. Whilst $11 \%$ lactose has been reported to be the optimal extender for liquid or frozen storage of camelid sperm (Morton et al. 2007; Wani et al. 2008) other studies report that tris-based extenders 
387

containing fructose or glucose are superior (Deen et al. 2003; Niasari-Naslaji et al. 2006; Vaughan et al. 2003; Vyas et al. 1998). Numerous extenders have been used for the cryopreservation of camelid sperm, and the results are conflicting and difficult to interpret as successful cryopreservation of sperm requires many factors to be optimised, including the most suitable cryodiluent reagents (i.e. energy source, glycerol concentration, egg yolk concentration), the optimal cooling, freezing and thawing and dilution rates of the sperm, and the optimal storage method (pellet or straws). In the present study, the final egg yolk concentration was $10 \%$ as is used routinely for ram sperm (Evans and Maxwell, 1987) and has been used for alpaca sperm (Morton et al. 2010 ; Santiani et al. 2005).The final glycerol concentration was $6 \%$ as this was found to be superior to $4 \%$ and $8 \%$ for cryopreservation of camel sperm (Niasari-Naslaji et al. 2007). In order toTo fully benefit from the optimised method for seminal plasma-viscosity reduction protocol using papain and E-64 it is necessary to systematically and thoroughly investigate the effect of all semen extender components on the integrity and function of alpaca sperm during and after cryopreservation. Furthermore, it is integral that fertilising ability of viscosity-reduced camelid semen is investigated to determine the effect of treatment on pregnancy.

In conclusion, the treatment of alpaca semen with $0.1 \mathrm{mg} / \mathrm{mL}$ papain for $20 \mathrm{~min}$ at $37^{\circ} \mathrm{C}$ followed by $10 \mu \mathrm{m} \mathrm{E}-64$ for $5 \mathrm{~min}$ at $37^{\circ} \mathrm{C}$ does not affect-impair sperm function and integrity in alpacas.. Furthermore, the treatment of alpaca semen with papain and E64 is beneficial to spermatozoa motility after chilling and at $0 \mathrm{~h}$ and $1 \mathrm{~h}$ post-thaw. This is most likely due to the ability of cryoprotectants to interact with or permeate the sperm cell membrane in samples with reduced viscosity compared to those with high viscosity.

The success of papain and E-64 in reducing semen viscosity and improving post-thaw motility rates without negatively impacting sperm function and integrity make this a promising solution to semen viscosity and could significantly aid the development of assisted reproductive technologies in camelids. 
414 The authors thank Kim Heasman for technical assistance, Byron Biffon and Keith Tribe for animal

415 husbandry and Professor Peter Thomson for help with statistical analysis. This research was

416 funded by the Rural Industries Research and Development Corporation (RIRDC) Australia and the 417 Australian Alpaca Association.

References

Adams, G. P., Ratto, M. H., Collins, C. W., and Bergfelt, D. R. (2009). Artificial insemination in South

American camelids and wild equids. Theriogenology. 71, 166-175.

Ali, H. A., Moniem, K. A., and Tingari, M. D. (1976). Some histochemical studies on the prostate, urethral and bulbourethral glands of the one-humped camel (Camelus dromedarius). Histochem.

J. 8, 565-578.

Barrett, A. J., Kembhavi, A. A., Brown, M. A., Kirschke, H., Knight, C. G., Tamai, M., and Hanada, K. (1982). L-trans-Epoxysuccinyl-leucylamido(4-guanidino)butane (E-64) and its analogues as inhibitors of cysteine proteinases including cathepsins B, H and L. Biochem. J. 201, 189-198. guanidino)butane] and related epoxides as inhibitors of cysteine proteinases. Acta. Biol. Med. Ger. 40, 1513-1517. alpaca semen and the effect of dilution rates on artificial insemination outcome. Arch. Androl. 43, 239-246.

436 Bravo, P. W., Skidmore, J. A., and Zhao, X. X. $\left(2000^{\mathrm{b}}\right)$. Reproductive aspects and storage of semen 437 in Camelidae. Anim. Reprod. Sci. 62, 173-193. 
Conde, P. A., Herrera, C., Trasorras, V. L., Giuliano, S. M., Director, A., Miragaya, M. H., Chaves, M.

G., Sarchi, M. I., Stivale, D., Quintans, C., Aguero, A., Rutter, B., and Pasqualini, S. (2008). In vitro production of llama (Lama glama) embryos by IVF and ICSI with fresh semen. Anim. Reprod. Sci.

$441 \quad 109,298-308$.

442 Crichton, E. G., Pukazhenthi, B. S., Billah, M., and Skidmore, J. A. (2015). Cholesterol addition aids 443 the cryopreservation of dromedary camel (Camelus dromedarius) spermatozoa. Theriogenology. $444 \quad 83,168-174$.

445 Deen, A., Vyas, S., and Sahani, M. S. (2003). Semen collection, cryopreservation and artificial 446 insemination in the dromedary camel. Anim. Reprod. Sci. 77, 223-233.

447 Evans, G., and Maxwell, W. M. C. (1987). 'Salamon's Artificial Insemination of Sheep and Goats' 448 (Butterworths: Sydney).

449 Garnica, J., Achata, R., and Bravo, P. W. (1993). Physical and biochemical characteristics of alpaca 450 semen. Anim. Reprod. Sci. 32, 85-90.

451 Giuliano, S., Carretero, M., Gambarotta, M., Neild, D., Trasorras, V., Pinto, M., and Miragaya, M. 452 (2010). Improvement of llama (Lama glama) seminal characteristics using collagenase. Anim. 453 Reprod. Sci. 118, 98-102.

454 Kershaw-Young, C. M., Evans, G., and Maxwell, W. M. (2012). Glycosaminoglycans in the 455 accessory sex glands, testes and seminal plasma of alpaca and ram. Reprod. Fertil. Dev. 24, 368456369.

457 Kershaw-Young, C. M., and Maxwell, W. M. C. (2011). The effect of seminal plasma on alpaca 458 sperm function. Theriogenology. 76, 1197-1206.

459 Kershaw-Young, C. M., Stuart, C., Evans, G., and Maxwell W. M. C. (2013). The effect of 460 glycosaminoglycan enzymes and proteases on the viscosity of alpaca seminal plasma and sperm 461 function. Anim. Reprod. Sci. 138, 261-267. 
Leahy, T., Celi, P., Bathgate, R., Evans, G., Maxwell, W. M., and Marti, J. I. (2010). Flow-sorted ram spermatozoa are highly susceptible to hydrogen peroxide damage but are protected by seminal plasma and catalase. Reprod. Fertil. Dev. 22, 1131-1140.

Morton, K. M., Bathgate, R., Evans, G., and Maxwell, W. M. (2007). Cryopreservation of epididymal alpaca (Vicugna pacos) sperm: a comparison of citrate-, Tris- and lactose-based diluents and pellets and straws. Reprod. Fertil. Dev. 19, 792-796.

Morton, K.M., Evans, G., and Maxwell, W. M. $\left(2010^{\mathrm{b}}\right)$. Effect of glycerol concentration, Equex $\mathrm{STM}^{\circledR}$ supplementation and liquid storage prior to freezing on the motility and acrosome integrity of frozen-thawed epididymal alpaca (Vicugna pacos) sperm. Theriogenology. 74, 311-316.

Morton, K. M., Thomson, P.C., Bailey, K., Evans, G., and Maxwell, W. M. $\left(2010^{\mathrm{a}}\right)$. Quality parameters for alpaca (Vicugna pacos) semen are affected by semen collection procedure. Reprod Domest Anim. 45, 637-643.

Morton, K. M., Vaughan, J., and Maxwell, W.M. (2008). 'Continued development of artificial insemination technology in alpacas'. (Rural Industries Research and Development Corporation: Kingston, Australia).

Niasari-Naslaji, A., Mosaferi, S., Bahmani, N., Gerami, A., Gharahdaghi, A.A., Abarghani, A., and Ghanbari, A. (2007). Semen cryopreservation in Bactrian camel (Camelus bactrianus) using SHOTOR diluent: effects of cooling rates and glycerol concentrations. Theriogenology. $\mathbf{6 8}, 618-$ 62.5 Niasari-Naslaji, A., Mosaferi, S., Bahmani, N., Gharahdaghi, AA., Abarghani, A., Ghanbari, A., and Gerami, A. (2006). Effectiveness of a tris-based extender (SHOTOR diluent) for the preservation of Bactrian camel (Camelus bactrianus) semen. Cryobiology. 51, 12-21.

Perk, K. (1962). Seasonal changes in the glandula bulbo-urethralis of the camel. Bull. Res. Counc. Isr. Sect. E Exp. Med. 10, 37-44. 
Santiani, A., Huanca, W., Sapana, R., Huanca, T., Sepulveda, N., and Sanchez R. (2005). Effects on

487 the quality of frozen-thawed alpaca (Lama pacos) semen using two different cryoprotectants and 488 extenders. Asian J. Androl. 7, 303-309.

489 Skidmore, J.A., and Billah, M. (2006). Comparison of pregnancy rates in dromedary camels

490 (Camelus dromedarius) after deep intra-uterine versus cervical insemination. Theriogenology. 66, $491 \quad 292-296$.

492 Tamai, M., Hanada, K., Adachi, T., Oguma, K., Kashiwagi, K., Omura, S., and Ohzeki, M. (1981).

493 Papain inhibitions by optically active E-64 analogs. J. Biochem. 90, 255-257.

494 Tibary, J., and Vaughan, J. (2006). Reproductive infertility and physiology in male South American 495 camelids: A review and clinical observations. Small Rum. Res. 61, 283-298.

496 Vaughan, J., Galloway, D., and Hopkins, D. (2003). 'Artificial Insemination in Alpacas (Lama

497 Pacos).' (Rural Industries Research and Development Corporation: Kingston, Australia).

498 Vyas, S., Goswani, P., Rai, A. K., and Khanna, N. D. (1998). Use of Tris and lactose extenders in

499 preservation of camel semen at refrigerated temperature. Indian Vet J. 75, 810-812.

500 Wani, N. A., Billah, M., and Skidmore, J. A. (2008), Studies on liquefaction and storage of

501 ejaculated dromedary camel (Camelus dromedarius) semen. Anim. Reprod. Sci. 109, 309-318.

502 Zhao, X. X. (2000), Semen characteristics and artificial insemination in the Bactrian camel. In:

503 Skidmore J. A. and Adams, G. P. eds. Recent Advances In Camelid Reproduction. International

504 Veterinary Information Service. 
Table 1.

Percentage motility (mean \pm SEM) of alpaca sperm treated with $0,0.001,0.01$ and $0.1 \mathrm{mg} / \mathrm{mL}$ papain at $0,5,10,20$ and 30 min of treatment.

\begin{tabular}{ccccc}
\hline $\begin{array}{c}\text { Time } \\
(\mathbf{m i n})\end{array}$ & $\begin{array}{c}\mathbf{0 . 0} \\
(\mathbf{m g} / \mathbf{m L})\end{array}$ & $\begin{array}{c}\mathbf{0 . 0 0 1} \\
(\mathbf{m g} / \mathbf{m L})\end{array}$ & $\begin{array}{c}\mathbf{0 . 0 1} \\
(\mathbf{m g} / \mathbf{m L})\end{array}$ & $\begin{array}{c}\mathbf{0 . 1} \\
(\mathbf{m g} / \mathrm{mL})\end{array}$ \\
\hline 0 & $56.0 \pm 2.30^{\mathrm{a}}{ }_{\mathrm{x}}$ & $56.0 \pm 2.30^{\mathrm{a}}{ }_{\mathrm{w}}$ & $56.0 \pm 2.30^{\mathrm{a}}{ }_{\mathrm{x}}$ & $56.0 \pm 2.30^{\mathrm{a}}{ }_{\mathrm{x}}$ \\
5 & $54.0 \pm 2.59^{\mathrm{a}}{ }_{\mathrm{x}}$ & $54.3 \pm 2.33^{\mathrm{a}}{ }_{\mathrm{wx}}$ & $56.5 \pm 2.85^{\mathrm{a}}{ }_{\mathrm{x}}$ & $55.7 \pm 2.12^{\mathrm{a}}{ }_{\mathrm{x}}$ \\
10 & $51.3 \pm 2.60^{\mathrm{a}}{ }_{\mathrm{y}}$ & $53.0 \pm 2.53^{\mathrm{ab}}{ }_{\mathrm{xy}}$ & $53.1 \pm 3.18^{\mathrm{ab}}{ }_{\mathrm{y}}$ & $54.33 \pm 2.53^{\mathrm{b}}{ }_{\mathrm{xy}}$ \\
20 & $48.7 \pm 2.56^{\mathrm{a}}{ }_{\mathrm{z}}$ & $51.7 \pm 2.57^{\mathrm{bc}}{ }_{\mathrm{y}}$ & $51.5 \pm 3.02^{\mathrm{b}}{ }_{\mathrm{yz}}$ & $53.7 \pm 2.41^{\mathrm{c}}{ }_{\mathrm{y}}$ \\
30 & $47.1 \pm 2.61^{\mathrm{a}}{ }_{\mathrm{z}}$ & $47.7 \pm 2.88^{\mathrm{a}}{ }_{\mathrm{z}}$ & $50.4 \pm 3.37^{\mathrm{b}}{ }_{\mathrm{z}}$ & $51.3 \pm 4.27^{\mathrm{c}}{ }_{\mathrm{y}}$ \\
\hline
\end{tabular}

$\overline{a, b, c}$ Within a row, means without a common superscript differed $(P<0.05)$

$w, x, y, z$ Within a column, means without a common subscript differed $(P<0.05)$ 
Table 2 .

Percentage motility (mean \pm SEM) of ejaculated alpaca sperm pre-dilution (Pre-D), post-dilution (PD), post-treatment (PT), post-chill (PC), and $0(0 \mathrm{~h}), 1(1 \mathrm{~h})$ and $3(3 \mathrm{~h})$ hours post-thaw when diluted then cryopreserved using fructose, fructose with papain, lactose, and lactose with papain extenders.

\begin{tabular}{ccccc}
\hline $\begin{array}{c}\text { Time } \\
\text { (min) }\end{array}$ & Fructose & $\begin{array}{c}\text { Fructose with } \\
\text { papain }\end{array}$ & Lactose & $\begin{array}{c}\text { Lactose with } \\
\text { papain }\end{array}$ \\
\hline Pre-D & $54.5 \pm 2.41^{\mathrm{a}}{ }_{\mathrm{u}, \mathrm{v}}$ & $54.5 \pm 2.41^{\mathrm{a}}{ }_{\mathrm{x}}$ & $54.5 \pm 2.41^{\mathrm{a}}{ }_{\mathrm{v}}$ & $54.5 \pm 2.41^{\mathrm{a}}{ }_{\mathrm{w}, \mathrm{x}}$ \\
PD & $65.5 \pm 3.29^{\mathrm{a}}{ }_{\mathrm{w}, \mathrm{x}}$ & $65.5 \pm 3.29^{\mathrm{a}}{ }_{\mathrm{w}}$ & $61.0 \pm 2.67^{\mathrm{a}}{ }_{\mathrm{v}}$ & $61.0 \pm 2.67^{\mathrm{a}}{ }_{\mathrm{x}}$ \\
PT & $61.5 \pm 2.89^{\mathrm{a}, \mathrm{b}}{ }_{\mathrm{v}, \mathrm{x}}$ & $63.5 \pm 3.25^{\mathrm{a}}{ }_{\mathrm{w}}$ & $42.5 \pm 5.69^{\mathrm{c}}{ }_{\mathrm{w}}$ & $54.5 \pm 2.41^{\mathrm{b}}{ }_{\mathrm{w}, \mathrm{x}}$ \\
PC & $47.0 \pm 4.29^{\mathrm{a}}{ }_{\mathrm{u}}$ & $51.5 \pm 2.69^{\mathrm{a}}{ }_{\mathrm{x}}$ & $32.5 \pm 6.75^{\mathrm{b}}{ }_{\mathrm{x}}$ & $48.1 \pm 5.08^{\mathrm{a}}{ }_{\mathrm{w}}$ \\
Oh & $19.0 \pm 2.69^{\mathrm{a}, \mathrm{b}}{ }_{\mathrm{y}}$ & $25.5 \pm 2.63^{\mathrm{a}}{ }_{\mathrm{y}}$ & $13.0 \pm 4.16^{\mathrm{b}}{ }_{\mathrm{y}}$ & $24.0 \pm 4.00^{\mathrm{a}}{ }_{\mathrm{y}}$ \\
1h & $16.5 \pm 3.25^{\mathrm{a}}{ }_{\mathrm{y}}$ & $26.0 \pm 3.06^{\mathrm{b}}{ }_{\mathrm{y}}$ & $7.2 \pm 2.86^{\mathrm{c}}{ }_{\mathrm{yz}}$ & $21.0 \pm 3.40^{\mathrm{a}, \mathrm{b}}{ }_{\mathrm{y}}$ \\
$3 \mathrm{~h}$ & $1.1 \pm 0.66^{\mathrm{a}}{ }_{\mathrm{z}}$ & $9.0 \pm 2.08^{\mathrm{a}}{ }_{\mathrm{z}}$ & $0.7 \pm 8.52^{\mathrm{a}}{ }_{\mathrm{z}}$ & $4.0 \pm 1.80^{\mathrm{a}}{ }_{\mathrm{z}}$
\end{tabular}

$\overline{a, b, c}$ Within a row, means without a common superscript differed $(P<0.05)$

$u, v, w, x, y, z$ Within a column, means without a common subscript differed $(P<0.05)$ 
Reproduction, Fertility and Development

Page 24 of 24

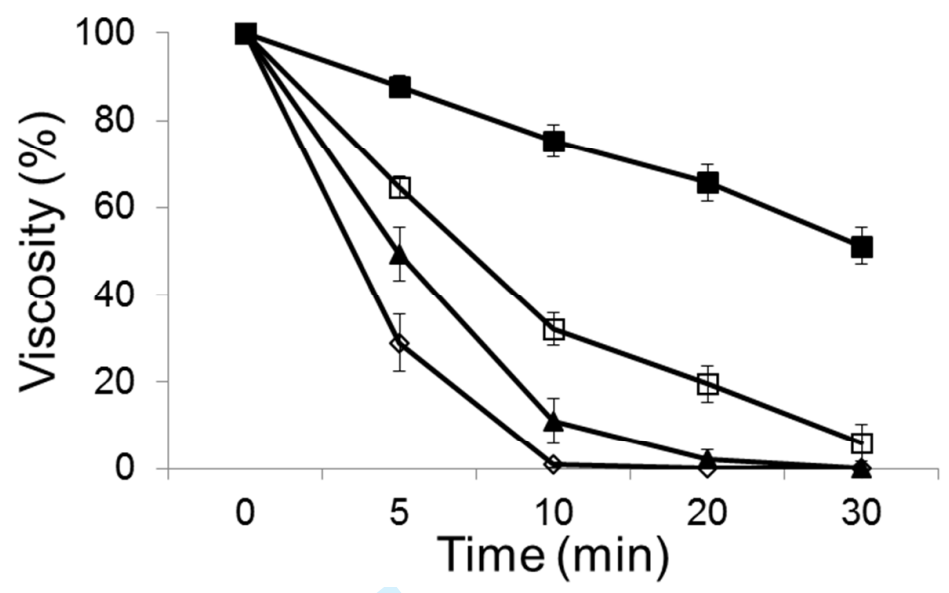

Fig. 1 Percentage viscosity (mean \pm SEM) of alpaca semen treated with 0 (control, $\square$ ), $0.001(\square)$, $0.01(\mathbf{\Delta})$ and $0.1(\diamond) \mathrm{mg} / \mathrm{mL}$ papain at $0,5,10,20$ and $30 \mathrm{~min}$ after treatment.

http://www.publish.csiro.au/journals/rfd 